\title{
Single sphere model fitting of supercritical carbon dioxide extraction from Quercus infectoria galls
}

\author{
Hasmida Mohd Nasir a , Liza Md Salleh a,b, ${ }^{*}$, Muhammad Syafiq Hazwan Ruslan ${ }^{\text {c, }}$ Mohd Amzar \\ Mohamed Zahari a \\ a Centre of Lipid Engineering and Applied Research (CLEAR), Ibnu Sina Institute for Scientific and Industrial Research (ISI-SIR), Universiti Teknologi \\ Malaysia, 81310 UTM Johor Bahru, Johor, Malaysia \\ b Bioprocess and Polymer Engineering Department, Faculty of Chemical and Energy Engineering, Universiti Teknologi Malaysia, 81310 UTM Johor \\ Bahru, Johor, Malaysia \\ c Department of Chemical Engineering, Universiti Teknologi PETRONAS, 32610 Bandar Seri Iskandar, Perak, Malaysia
}

* Corresponding author: i.liza@cheme.utm.my

\section{Article history}

Received 19 November 2017

Accepted 6 December 2017

\begin{abstract}
Q. infectoria galls, locally knowns as 'manjakani' in Malaysia and Indonesia, is a traditional medicine commonly used for postpartum recovery due to its strong astringency. The astringent properties of $Q$. infectoria galls is due to the high amount of tannin available in the extract. In this study, supercritical carbon dioxide $\left(\mathrm{SC}-\mathrm{CO}_{2}\right)$ with the presence of absolute methanol (1:3 $\mathrm{w} / \mathrm{v}$ ) was used for the extraction of $Q$. infectoria galls. The $\mathrm{SC}-\mathrm{CO}_{2}$ extraction of the galls involve the diffusion and mass transfer process, represented by the value of diffusion coefficient $\left(D_{e}\right)$ and the external mass transfer coefficient $\left(k_{f}\right)$. Single sphere model (SSM) was adapted and fitted into the experimental data, and $D_{e}$ was found to be in the range of $0.91 \times 10^{-11}$ to $9.99 \times$ $10^{-11} \mathrm{~m}^{2} / \mathrm{s}$. The linear driving force approximation was used to determine the $k_{f}$ values, which calculated to be in the range of $4.60 \times 10^{-6}$ to $9.50 \times 10^{-6} \mathrm{~m} / \mathrm{s}$. SSM also pointed out that the SC$\mathrm{CO}_{2}$ extraction of $Q$. infectoria galls is governed by internal diffusion with Biot number $(B I)$ greater than 10 .
\end{abstract}

Keywords: Quercus infectoria, supercritical fluid extraction, single sphere model

\section{INTRODUCTION}

Q. infectoria (manjakani) is a type of medicinal plant that can be used in treating diseases and it is already well-known since ancient time. Oak (Quercus) is a part of Fagaceae family. Referring to Mills and Bone (2000), galls are strongly astringent due to their high content of tannin. Besides, Wiart and Kumar (2001) and Bruneton (1995) were in agreement with each other, where they reported the galls contains tannin $(50-70 \%)$, gallic acid $(2-4 \%)$ and ellagic acid. Astrigency offers protection of the sub-adjacent layers of mucosa from microorganisms and irrritant chemicals, and antisecretory effect. They are applied for arrest haemorrhage from the nose or gums, and haemorrhoids. The galls can also be used in treating diarrhoea, dysentery, and leucorrhea (Sariozlu and Kivanc, 2011). Q. infectoria galls are also traditionally used as dental powder in the treatment of gingivitis and toothache. The galls extract also proven to have antibacterial (Leela and Satirapipathkul, 2011), larvicidal (Aivazi and Vijaya, 2009), anti-inflammatory (Kaur et al., 2004) and antioxidant quality (Tian et al., 2009).

Supercritical fluid extraction (SFE) has been used for many years to isolate volatile compounds such as aroma compounds and essential oils from the plant materials. This method has been proven to be able to reduce the use of harmful solvents as well as shorten the extraction time of the process. Implementation of supercritical fluid (SCF) as extraction solvent provides higher efficiency and faster mass transfer rate from matrix into the extraction fluid compared to ordinary liquid solvents. Theoretically, SCF does not have any advantages over liquid solvents in term of dissolving power. It only approaches that of a liquid solvent when the density is high enough. However, the excellent mass transfer makes the extraction using SCF as a solvent a superior method. The rate of mass transfer determines the rate at which extraction can be accomplished. Solute diffusivities in supercritical fluids are typically ten times higher than those of liquid solvents and their viscosity is lower by one order magnitude, so their mass transfer properties are much more favourable than those of liquids (Amajuoyi, 2001). In other perspective, SFE is much faster process than liquid extraction because the extraction process using SCF can be completed within some fractions of an hour meanwhile liquid solvents extraction normally lasts for several hours.

The extraction from natural materials such as plant, seed or nut may involve diffusion and mass transfer process due to the occurrence of releasing solutes from porous or cellular solid matrices into solvent. Treybal (1981) defined mass transfer as the net mass movement from one location to another, i.e. phases during the extraction process, depending on the differences in chemical potential. It is mainly used to explain the physical processes of chemical species involving diffusive and convective transport. Mass transfer is thermodynamically described in the term of rate function, which depends on substance diffusivities and flow pattern within the system. 
Mathematical modelling is an essential step in extraction process for optimization, design and process development (Moura et al., 2012). Döker et al. (2010) mentioned that the selection of models is based on the distribution of extractable solute within the particle structure, either they are accessible on the solid surface, adsorbed on the outer surface, located within pores or dispense within the plant cells uniformly. The aim of this work is to determine diffusion and mass transfer coefficient of the extraction process of the galls by fitting the single sphere model (SSM) on the experimental data. SSM was selected due to its simplicity to describe the extraction process.

\section{METHODOLGY}

\section{Chemicals}

Liquid carbon dioxide used in the supercritical extraction system (99.9\% purity) was purchased from Kras Instrument, Johor, Malaysia. Analytical grade of methanol (99.8\%) was obtained from QRëC (Asia) Sdn Bhd, Selangor.

\section{Plant material}

The $Q$.infectoria galls were bought from local market in Kota Tinggi, Johor, Malaysia. The galls were separated, rinsed using tap water to remove unwanted material and dried in an oven at $50^{\circ} \mathrm{C}$ overnight. They were ground using a blender (WARING $\circledast$, Connecticut USA) and sieved into various particle sizes for further analysis. The prepared galls were stored in a freezer $\left(-20^{\circ} \mathrm{C}\right)$.

\section{Extraction procedure}

Supercritical carbon dioxide $\left(\mathrm{SC}-\mathrm{CO}_{2}\right)$ extraction experiments were performed using extraction systems implemented in CLEAR lab. The system consists of: $50 \mathrm{~mL}$ extraction vessel (dimensions: $1.4 \mathrm{~cm}$ internal diameter, $33 \mathrm{~cm}$ long), high pressure $\mathrm{CO}_{2}$ pump (Supercritical 24, Lab Alliance), automated back pressure regulator (Jasco BP 2080 Plus Automated BPR), and oven (Memmert). Liquid $\mathrm{CO}_{2}$ is supplied from a gas cylinder. Extraction was conducted under three independent variables; pressures $(20-30 \mathrm{MPa})$, temperatures $\left(50-70^{\circ} \mathrm{C}\right)$ and mean particle sizes ( 0.50 to $1.50 \mathrm{~mm})$. Absolute methanol $(\mathrm{MeOH})$ was used as a modifier to enable the extraction of the polar compounds from the solid matrix in $\mathrm{SC}_{-} \mathrm{CO}_{2}$ systems. $5.00 \pm 0.0100 \mathrm{~g}$ of the grounded $Q$. infectoria galls mixed with methanol at the ratio of $1: 3(\mathrm{w} / \mathrm{v})$ were inserted into the extraction vessel and was placed in an oven to keep the operating temperature. $\mathrm{CO}_{2}$ was pumped into the vessel until the required pressure was achieved. The extraction was done using static extraction for 30 minutes and dynamically for 80 minutes at the $\mathrm{CO}_{2}$ flow rate of $2 \mathrm{~mL} / \mathrm{min}$ (Salleh et al., 2014). Static extraction method was done due to the nature of the galls where the oil is mostly located within the particle. It allows more penetration time into the particles and dissolves large amount of substances (Ferdosh et al., 2011). Whereas, dynamic method was performed to ensure complete extraction process of the galls. The extract was collected in a vial and the solvent was evaporated in an oven. The extract was weighed and the amount of extracted yield was measured gravimetrically. The obtained extracts were transferred into a glass bottle and kept in a freezer $\left(-4^{\circ} \mathrm{C}\right)$.

\section{Model fitting}

Single sphere model which was introduced by Crank (1975) considers the relationship between the size of particle and diffusion coefficient. High diffusion coefficient indicates that good extraction phenomena have been obtained. The assumptions made are (Bartle, 1990; Reverchon et al., 1993):

i) Intraparticle mass transfer is the controlling factor in the extraction process

ii) Mass transfer resistance on the fluid is zero

iii) Solute is extracted from particulate bed composed of porous inert sphere

iv) Size of sphere is similar

v) Entire particles in the bed are at the same stage of extraction vi) Components to be extracted move through the particles by process 'similar to diffusion'

The basic equation for the rate of solute that transport radially across an internal surface within spherical and isotropic particle takes the form of Fick's law as:

$$
\text { Rate }=-4 \pi r^{2} D_{e}\left(\frac{\partial q}{\partial r}\right)
$$

where,

$q \quad=$ Solute concentration inside the particle at radius $\mathrm{r}(\mathrm{kg}$ solute/ $\mathrm{m}^{3}$ of particle)

$D_{e} \quad=$ Effective diffusivity

The equation given by Crank (1975) to solve the diffusion coefficient is:

$$
Y^{\prime}=\frac{M_{t}}{M_{\infty}}=1-\frac{6}{\pi^{2}} \sum_{n-1}^{\infty} \frac{1}{n^{2}} \exp \frac{D_{e} t n^{2} \pi^{2}}{R^{2}}
$$

Where, $M_{t}$ is the total amount of solute diffused from sphere at time t, $M_{\infty}$ is the total amount of solute, $n$ is the number of iterations, $D_{e}$ is the diffusion coefficient, $R$ is the particle radius, and $t$ is time.

Various approaches successfully done in the literature can be adapted to model the supercritical fluid extraction. In this study, in conjunction with SSM, linear adsorption equilibrium model was used in order to determine the mass transfer coefficients of the extraction process.

The assumption that has been used in this case is the combined internal and external mass transfer processes are well described by a linear driving force approximation which is derived by assuming a parabolic concentration profile within the particle (Goto et al., 1990). Thus, the overall mass transfer coefficient, $k_{p}$ for sphere geometry particle is given by Equation 3 with the Biot number, $B_{i}=\frac{k_{f} r}{D_{e}}$.

$$
k_{p}=\frac{k_{f}}{1+B_{i} / 5}
$$

The external mass transfer coefficient $\left(k_{f}\right)$ can be calculated using Sherwood number, $S h$.

$$
S h=\frac{k_{f} d}{D e}
$$

Usually, Sherwood number is written as a function of Reynolds number, $R e=\frac{\rho v d}{\mu}$ and Schmidt number, $S c=\frac{\mu}{\rho D_{e}}$, where $\rho$ is the solvent density. The correlation that applicable over the range of $R e$ from 3to 3000 and $S c$ from 0.5 to 10,000 is represented by (Wakao and Funazkri, 1978):

$$
S h=2+1.1 R e^{0.6} S c^{0.33}
$$

While the correlation is valid over supercritical velocities from $4.4 \times 10^{-3}$ to $3.1 \times 10^{-2} \mathrm{~cm} / \mathrm{s}$, Re from 2 to 40 and $S c$ from 2 to 40 (Reverchon and Senator, 1992) is given by:

$$
S h=0.38 R e^{0.83} S c^{0.33}
$$

Based on the equations, various parameters including physical and mass transfer properties are needed in order to compute the extraction yield. The physical properties of the galls such as particle density $\left(\rho_{s}\right)$ and apparent density $\left(\rho_{b}\right)$, were obtained experimentally. The porosity $(\varepsilon)$ of the grounded dried raw material was calculated from from $\varepsilon=1$ $\left(\rho_{b} / \rho_{s}\right)$. Specific surface area per unit volume of extraction bed $\left(\alpha_{0}\right)$ obtained from $\mathrm{a}_{0}=6(1-\varepsilon) / \mathrm{d}$. Chung (1988) method is relevant for computation of viscosity values of the solvent systems studied (Poling 
et al., 2001). In this study, the density and viscosity of the solvent were calculated by considering the mixture of $\mathrm{CO}_{2}$ and methanol.

The basic equation for the rate of solute that transport radially across an internal surface within spherical and isotropic particle takes the form of Fick's law as:

\section{RESULTS AND DISCUSSION}

The value of effective diffusion coefficient, $D_{e}$ was estimated by plotting the graph of cumulative yield, $\mathrm{M}_{\mathrm{t}} / \mathrm{M}_{\infty}$ against the extraction time for both experimental data and model curves (Fig. 1). The best $D_{e}$ was selected by the best fit curve with high regression coefficient, $\mathrm{R}^{2}$ and lowest average absolute relative deviation (AARD). This value is then used in subsequent equations of $R e, S c, S h$ and $B i$ to evaluate the external and overall mass transfer coefficient, $k_{f}$ and $k_{p}$, respectively. From the figure, it can be noticed that only short extraction time needed for the solute to reach asymptotic extraction yield, attributed by static method applied at the beginning of the extraction process before collecting the extract. This technique involves holding the sample with $\mathrm{CO}_{2}$ and allows more penetration time into the particle and dissolves large amount of substance (Ferdosh et al., 2011).

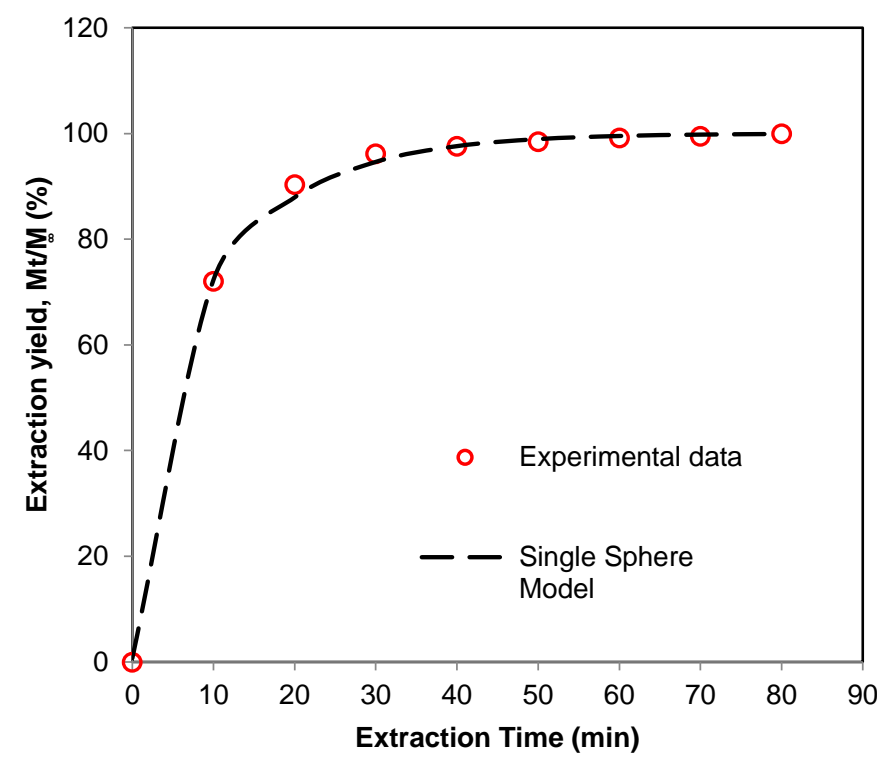

Fig. 1 Single sphere model for $\mathrm{SC}-\mathrm{CO}_{2}$ extraction of the galls at $20 \mathrm{MPa}$, $70^{\circ} \mathrm{C}$ and $1.00 \mathrm{~mm}$; fitted value $D_{e}=3.41 \times 10^{-11} \mathrm{~m}^{2} \mathrm{~s}^{-1}$

According to Esquível et al. (1999), the general equation of single sphere model (SSM) is applicable for high velocity but fail to represent the extraction behaviour at low velocity $\left((0.1-1.3) \times 10^{-4} \mathrm{~m} / \mathrm{s}\right)$. The statement explains good fitting and correlation as shown in this study as the values of solvent velocity ranging from $4.09 \times 10^{-4}$ to $4.33 \times 10^{-4}$ $\mathrm{m} / \mathrm{s}$. This is due to SSM which mainly focused on the solute extraction inside the particles, assuming the easily accessible oil have been removed from the galls.

The dependency of extraction rate on pressure is typical in which solvent density and solvent power is crucial for solving substances. The supercritical solvent extraction on the galls was done at 20 to $30 \mathrm{MPa}$ to investigate the effect of pressure on mass transfer at $70^{\circ} \mathrm{C}$ and 1.00 $\mathrm{mm}$. Generally, the increase in solvent solubility with pressure will increase the driving force and extraction rate of the galls. Based on Table 1, effective diffusion coefficient, $D_{e}$ shows no systematic dependence on $\mathrm{CO}_{2}$ velocity $\left(4.33 \times 10^{-4} \mathrm{~m} / \mathrm{s}\right)$ but increases at elevated pressure by approximately one order magnitude for every $5 \mathrm{MPa}$ differences, from $3.41 \times 10^{-11} \mathrm{~m}^{2} / \mathrm{s}$ at $20 \mathrm{MPa}$ to $6.14 \times 10^{-11} \mathrm{~m}^{2} / \mathrm{s}$ at 30 $\mathrm{MPa}$. In addition, mass transfer coefficient in fluid phase, $k_{f}$ and overall mass transfer coefficient, $k_{p}$ increases with pressure due to direct connection with $D_{e}$. This effect of pressure is in contrast with the research on neem seeds extraction using supercritical $\mathrm{CO}_{2}$ where the optimum $k_{f}$ decreases from $16.4 \times 10^{-6}$ to $1.23 \times 10^{-6} \mathrm{~m} / \mathrm{s}$ at pressure level of 10 to $26 \mathrm{MPa}$ (Mongkholkhajornsilp et al., 2005).

The effect of extraction temperature on calculated extraction rate at $30 \mathrm{MPa}$ and $1.00 \mathrm{~mm}$ is tabulated in Table 1. The role of supercritical solvent viscosity is notable in temperature effect where it increases with temperature which leads to better penetration of solvent into the solute. The $D_{e}$ values were determined as $4.32 \times 10^{-11}, 5.63 \times 10^{-11}$ and $6.14 \times 10^{-}$ $11 \mathrm{~m}^{2} / \mathrm{s}$ for 50,60 and $70^{\circ} \mathrm{C}$, respectively. In fact, the addition of methanol at the beginning of the extraction help to increase the interaction between solute and modifier thus influence the solute diffusion significantly (Jin et al., 2012). For mass transfer coefficient in the fluid phase, $k_{f}$, the values were ranging from $6.76 \times 10^{-6}$ to $8.20 \times 10^{-}$ ${ }^{6} \mathrm{~m} / \mathrm{s}$ at increasing temperature. The reasons for the observed results were due to the reduction in mass transfer resistance and increase in convection (Döker et al., 2010). Low resistance in mass transfer caused the solute easily accessible to the solvent, thus, causing a rise in solute solubility that leads to the increment of extraction rates and better solute content as the temperature is increased from $50^{\circ} \mathrm{C}$ to $70^{\circ} \mathrm{C}$. The enhancement of mass transfer rate with temperature was also reported for the extraction of rosemary (Bensebia et al., 2009), canola seeds and sesame seeds (Honarvar et al., 2013).

Study on particle size effect towards extraction rate was performed using three different mean sizes which are $0.50 \mathrm{~mm}, 1.00 \mathrm{~mm}$ and 1.50 $\mathrm{mm}$ at pressure of $20 \mathrm{MPa}$ and temperature of $50^{\circ} \mathrm{C}$. The adjustable and fitting parameters are tabulated in Table 1 . The increase in mean particle size from $0.50 \mathrm{~mm}$ to $1.50 \mathrm{~mm}$ caused the external mass transfer coefficient to increase to $9.50 \times 10^{-6} \mathrm{~m} / \mathrm{s}$. The finding suggests the occurrence of bed caking and channelling exist in the extraction vessel when smaller geometry was used owing to the application of modifier and static time during the extraction. Thus, resulting to inhomogeneous extraction process and insufficient contact between solute and solvent molecules, leading to the decrease mass transfer rate. The observation is similar with Huang et al. (2016) who reported a good simulation of Crank model for Chinese lantern extraction. The study reveals the analyte diffusion coefficient decrease from $5.59 \times 10^{-13}$ to $0.21 \times 10^{-13} \mathrm{~m}^{2} / \mathrm{min}$ with particle size reduces, which in turn drop the mass transfer resistance.

Decreasing $D_{e}$ indicates the difficulty of supercritical solvent to diffuse into the pores of particle to dissolve the solute and implies that the mass transfer resistance is mainly located in the solid phase (Liza, 2010). Meanwhile, increasing $k_{f}$ value which represents less mass transfer resistance existed within the particle leads to easy transportation process of the solute. The $k_{f}$ value of this study was satisfying compared to those in Boutin et al. (2011) where the external mass transfer coefficient for rapeseeds and sunflower seeds extraction were in order of $\times 10^{-5} \mathrm{~m} / \mathrm{s}$. The difference might be due to the nature of the seeds and extraction procedure. The average absolute relative deviation (AARD) was found to vary from $2.99 \%$ to $18.27 \%$. These values were acceptable and agreed with Esquível et al. (1999) who reported the maximum accepted mean deviation calculated from single sphere model was found to be $23.6 \%$. In addition, the Biot numbers (Bi) for all variables in this study are greater than 10 , indicating that internal diffusion is the controlling factor of the extraction process. Hence, $D_{e}$ values can be further utilized in designing the extraction process of the galls. Similar occurrence is reported by Macías-Sánchez et al. (2009) in which the intraparticle diffusion is an essential factor for carotenoids extraction due to large Biot number range varied from $10^{7}$ to $10^{10}$ for both binary and ternary solvent systems. In fact, this observation is reasonable since the initial concern of SSM is solute extraction within the particle (Esquível et al., 1999).

\section{CONCLUSION}

From this research, single sphere model (SSM) pointed out that internal diffusion as the governing factor in the supercritical fluid extraction of the galls with Biot number, $B i$ greater than 10 . The diffusion coefficient, $D_{e}$ was ranging from $0.91 \times 10^{-11}$ to $9.99 \times 10^{-11} \mathrm{~m}^{2} / \mathrm{s}$ and $k_{f}$ values $\left((4.60-9.50) \times 10^{-6} \mathrm{~m} / \mathrm{s}\right)$. The value of all adjustable parameters increases with increase in pressure, temperature and mean particle size. 
Table 1 Calculated parameters for the mass transfer using single sphere model for Q.infectoria galls.

\begin{tabular}{|c|c|c|c|c|c|c|c|c|c|c|c|c|}
\hline $\begin{array}{c}\mathrm{P} \\
(\mathrm{MPa})\end{array}$ & $\begin{array}{c}\mathrm{T} \\
\left({ }^{\circ} \mathrm{C}\right)\end{array}$ & $\underset{(\mathrm{mm})}{\mathrm{d}}$ & $\begin{array}{l}D_{e} \times 10^{11} \\
\left(\mathrm{~m}^{2} \mathrm{~s}^{-1}\right)\end{array}$ & $\begin{array}{c}\mu \times 10^{5} \\
\left(\mathrm{kgm}^{-1} \mathrm{~s}^{-1}\right)\end{array}$ & $\begin{array}{l}u \times 10^{4} \\
\left(\mathrm{~ms}^{-1}\right)\end{array}$ & $R e$ & Sc & $S h$ & $B i$ & $\begin{array}{l}k_{f} \times 10^{6} \\
\left(\mathrm{~ms}^{-1}\right)\end{array}$ & $\begin{array}{l}k_{p} \times 10^{7} \\
\left(\mathrm{~ms}^{-1}\right)\end{array}$ & $\begin{array}{c}\text { AARD } \\
(\%)\end{array}$ \\
\hline 20 & 70 & 1.00 & 3.41 & 1.6756 & 4.33 & 171.81 & $7.38 \times 10^{2}$ & $1.55 \times 10^{2}$ & 77.56 & 5.29 & 3.21 & 6.11 \\
\hline 25 & 70 & 1.00 & 4.55 & 1.6756 & 4.33 & 190.42 & $5.00 \times 10^{2}$ & $1.45 \times 10^{2}$ & 72.52 & 6.60 & 4.26 & 10.72 \\
\hline 30 & 70 & 1.00 & 6.14 & 1.6756 & 4.33 & 202.92 & $3.48 \times 10^{2}$ & $1.34 \times 10^{2}$ & 66.85 & 8.20 & 5.71 & 5.40 \\
\hline 30 & 50 & 1.00 & 4.32 & 1.5823 & 4.33 & 237.28 & $4.23 \times 10^{2}$ & $1.57 \times 10^{2}$ & 78.32 & 6.76 & 4.06 & 18.27 \\
\hline 30 & 60 & 1.00 & 5.63 & 1.6292 & 4.33 & 220.09 & $3.50 \times 10^{2}$ & $1.41 \times 10^{2}$ & 70.31 & 7.92 & 5.25 & 7.53 \\
\hline 30 & 70 & 1.00 & 6.14 & 1.6756 & 4.33 & 202.92 & $3.48 \times 10^{2}$ & $1.34 \times 10^{2}$ & 66.85 & 8.20 & 5.71 & 5.40 \\
\hline 20 & 50 & 0.50 & 0.91 & 1.5823 & 4.98 & 124.06 & $2.22 \times 10^{3}$ & $2.54 \times 10^{2}$ & 127.10 & 4.60 & 1.74 & 2.99 \\
\hline 20 & 50 & 1.00 & 3.74 & 1.5823 & 4.33 & 215.76 & $5.98 \times 10^{2}$ & $1.60 \times 10^{2}$ & 80.04 & 5.98 & 3.52 & 10.98 \\
\hline 20 & 50 & 1.50 & 9.99 & 1.5823 & 4.09 & 305.65 & $2.01 \times 10^{2}$ & $1.43 \times 10^{2}$ & 71.32 & 9.50 & 6.22 & 6.92 \\
\hline
\end{tabular}

Effective intraparticle diffusion coefficient $\left(D_{e}\right)$, viscosity mixture $(\mu)$, interstitial fluid velocity $(u)$, Reynolds number $(R e)$, Schmidt number $(S c)$, Sherwood number $(S h)$, Biot number $(B i)$, mass transfer coefficient in the fluid phase $\left(k_{f}\right)$, overall mass transfer coefficient $\left(k_{p}\right)$, average absolute relative deviation (AARD), regression coefficient $\left(R^{2}\right)$.

\section{ACKNOWLEDGEMENT}

The authors acknowledge Ministry of Higher Education, Malaysia and Universiti Teknologi Malaysia for funding this project by Research University Grant (04H04), and Centre of Lipid Engineering and Applied Research (CLEAR) for the use of equipment.

\section{REFERENCES}

Aivazi, A. A., Vijaya, V. A. 2009. Larvicidal activity of oak Quercus infectoria oliv. (Fagacea) gall extracts against Anopheles stephensi liston. Parasitol. Res. 104, 1289-1293.

Amajuoyi, I. K. 2001. Behavior and elimination of pesticide residues during supercritical carbon dioxide extraction of essential oils of spice plants and analysis of pesticides in high-lipid-content plant extracts. PhD Thesis. Institut für Lebensmitteltechnologie und Analytische Chemie, Technische Universität München.

Bartle, K. D., Clifford, K. P., Hawthorne, S. B., Langenfeld, J. J., Miller, D. J., Robinson, R. A. 1990. Model for dynamic extraction using supercritical fluids. J. Supercrit. Fluids. 3, 143-149.

Bensebia, O., Barth, D., Bensebia, B., Dahmani, A. 2009. Supercritical $\mathrm{CO}_{2}$ extraction of rosemary: effect of extraction parameters and modelling. $J$. Supercrit. Fluids. 49, 161-166.

Boutin, O., De Nadai, A., Perez, A. G., F, J, H., Beltran, M., Badens, E. 2011 Experimental and modelling of supercritical oil extraction from rapeseeds and sunflower seeds. Chem. Eng. Res. Des. 89, 2477-2484.

Bruneton, J. 1995. Pharmacognosy, Phytochemistry, Medicinal Plants. Paris: Lavoisier.

Chung, T. H. 1988. Generalized multiparameter correlation for nonpolar and polar fluid properties. Ind. Eng. Chem. Res. 27(4), 671-678.

Crank, J. 1975. The Mathematics of Diffusion. Oxford: Clarendon.

Döker, O., Salgin, U., Yildiz, N., Aydoğmuş, M., Çalimli, A. 2010. Extraction of sesame seed oil using supercritical $\mathrm{CO}_{2}$ and mathematical modeling. $J$. Food Eng. 97, 360-366.

Esquível, M. M., Bernardo-Gil, M. G., King, M. B. 1999. Mathematical models for supercritical extraction of olive husk oil. J. Supercrit. Fluids. 16, 4358.

Ferdosh, S., Sarker, M. Z. I., Karim, M. R., Akanda, M. J. H., Selamat, J. 2011 Fish oil recovery from viscera of indian mackerel (Rastrelliger kanagurta) by supercritical fluid: An optimization approach. J. Chin. Chem. Soc. 59, 1421-1429.

Goto, M., Smith, J. M., McCoy, B. J. 1990. Parabolic profile approximation (linear driving-force model) for chemical reactions. Chem. Eng. Sci. 45, 445-448.

Honarvar, B., Sajadian, S. A., Khorram, M., Samimi, A. 2013. Mathematical modeling of supercritical fluid extraction of oil form canola and sesame seeds. Braz. J. Chem. Eng. 30 (1), 159-166.

Huang, Z., Yang, M. J., Ma, Q. L., Liu, S. F. 2016. Supercritical $\mathrm{CO}_{2}$ extraction of chinese lantern: Experimental and OEC modelling. Sep. Purif. Technol. $159,23-34$.
Jin, J. S., Wang, Y. B., Zhang, Z. T., Liu, H. T. 2012. Solubilities of benzene sulfomide in supercritical $\mathrm{CO}_{2}$ in the absence and presence of cosolvent. Thermochim. Acta. 527, 165-171.

Kaur, G., Hamid, H., Ali, A., Alam, M.S., Athar, M. 2004. Antiinflammatory evaluation of alcoholic extract of galls of Quercus infectoria. J. Ethnopharmacol. 90, 285-292.

Leela, T., Satirapipathkul, C. 2011.Studies on the antibacterial activity of Quercus infectoria galls. Paper presented at International Conference on Bioscience, Biochemistry and Bioinformatics, IPCBEE vol. 5. IACSIT Press, Singapore, 410-414.

Liza M. S. 2010. Extraction of bioactive flavonoid compounds from pecah kaca (Strobilanthes crispus) using Supercritical Carbon Dioxide. PhD Thesis. Universiti Putra Malaysia, Serdang, Selangor, Malaysia.

Macías-Sánchez, M. D., Serrano, C. M., Rodríguez, M. R., de la Ossa, E. M. 2009. Kinetics of the supercritical fluid extraction of caretenoids form microalgae with $\mathrm{CO}_{2}$ and ethanol as cosolvent. Chem. Eng. J. 150, 104113.

Mills, S., Bone, K. 2000. Principles and Practice of phytotheraphy: Modern herbal medicine. London, UK: Harcourt Publishers Ltd.

Mongkholkhajornsilp, D., Douglas, S., Douglas, P. L., Elkamel, A., Teppaitoon, W., Pongamphai, S. 2005. Supercritical $\mathrm{CO}_{2}$ extraction of nimbin form neem seeds-A modelling study. J. Food Eng. 71, 331-340.

Moura, P. M., Prado, G. H. C., Meireles, M. A. A., Pereira, C. G. 2012. Supercritical fluid extraction from guava (Psidium guajava) leaves: Global yield, composition and kinetic data. J. Supercrit. Fluids. 62, 116-122.

Reverchon, E., Donsi, G., Osse'o, L. S. 1993. Modeling of supercritical fluid extraction from herbaceous matrices. Ind. Eng. Chem. Res. 32, 2721-2726.

Reverchon, E., Senator, F. 1992. Isolation of rosemary oil: Comparison between hydrodistillation and supercritical $\mathrm{CO}_{2}$ extraction. Flavour Fragr. J. 7 , 227-230.

Salleh, L. M., Mohd Nasir, H., Yaakob, H., Yunus, M. A. C. 2014. Determination of supercritical carbon dioxide extraction parameters for Quercus infectoria galls and the effects on extraction yiels and antioxidant activity. Jurnal Teknologi. 67(2), 1-4.

Sariozlu, N. Y., Kivanc, M. 2011. Chapter 60: Gallnuts (Quercus infectoria Oliv. and Rhus chinensis Mill.) and their usage in health. In Preedy et al. Nuts and Seeds in Health and Disease Prevention. (505-511). United States of America: Academic Press, Elsevier.

Tian, F., Li, B., Ji, B., Yang, J., Zhang, G., Chen, Y. 2009. Antioxidant and antimicrobial activities of consecutive extracts from Galla chinensis: The polarity affects the bioactivities. Food Chem. 113, 173-179.

Treybal, R. E. 1981. Mass-Transfer Operations. ( ${ }^{\text {rd }}$ Ed.). Singapore: McGrawHill Inc.

Wakao, N., Funazkri, T. 1978. Effect of fluid dispersion coefficients on particleto-fluid mass transfer coefficients in packed beds: correlation of sherwood numbers. Chem. Eng. Sci. 33 (10), 1375-1384.

Wiart, C., Kumar, A. 2001. Practical handbook of pharmacognosy. Malaysia: Pearson Education Malaysia Sdn. Bhd. 